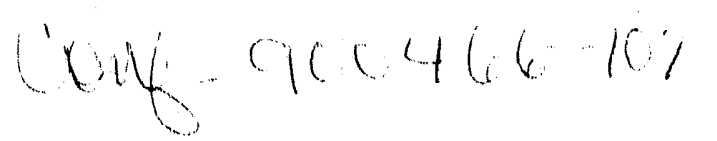

WSRC-RP-89-1285

\title{
MAGNETIC RESONANCE AS A STRUCTURAL PROBE OF A URANIUM (VI) SOL.GEL PROCESS (U)
}

by

C.M. King 1 , R.B. King ${ }^{2}$, A.R. Garber ${ }^{3}$, M. C. Thompson ${ }^{1}$ and B. R. Buchanan 1

1 Westinghouse Savannah River Company

Savannah River Site

Aiken, SC

2Department of Chemistry

University of Georgia

Athens, GA

${ }^{3}$ Department of Chemistry

University of South Carolina

Columbia, SC

A paper proposed for presentation at the

Materials Research Society: Better Ceramics Through

Chemistry IV Symposium

San Francisco, CA

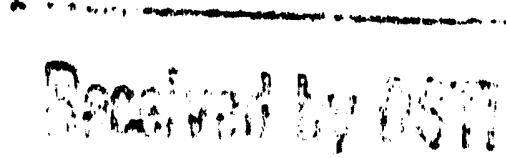

April 16-21, 1990

$\therefore$ : $2: 1932$

and for publication in the Proceedings

The information contained in this paper was developed during the course of work under Contract No. DE-AC09-76SR(0)001 (now Contract No. DE-ACO9-88SR 18035) with the U.S. Department of Energy. By acceptance of this paper, the publisher and/or recipient acknowledges of the U.S. Government's right to retain a nonexclusive, royalty-free license in and to any copyright covering this paper, along with the right to reproduce and to atuthorize others to reproduce all or part of the copyrighted paper. 


\section{DISCLAIMER}

This report was prepared as an account of work sponsored by an agency of the United States Government. Neither the United States Government nor any agency therenf, nor any of their employees, makes any warranty, express or implied, or assumes any legal liability or responsibility for the accuracy, completeness, or usefulness of any inforrination, apparatus, product, or process disclosed, or represents that its use would not inffringe privately owned rights. Reference herein to any specific commercial product, process, or service by trade name, tradernark, manufacturer, or otherwise does not necessarily constitute or imply its endorsement, recommendation, or favoring by the United States Government or any agency thereof. The views and opinions of authors expressed herein do not necessarily state or reflect those of the United States Government or any agency thereof.

This report has been reproduced directly from the best available copy.

Available to DOE and DOE contractors from the Office of Scientific and Technical Information, P.O. Box 62, Oak Ridge, TN 37831; prices available from (615) 576-8401, FTS 626-8401.

Available to the public from the National Techncial Information Service, U.S. Department of Commerce. 5285 Port Royal Rd., Springfield, VA 22161. 


\section{MAGNETIC RESONANCE AS A STRUCTURAL PROBE OF A URANIUM (VI) SOL-GEL PROCESS}

Charles M. King*, R. Bruce King**, A. Ronald Garber***, M. C. Thompson* and B. R.
Buchanan*

*Westinghouse Savannah River Company, Aiken, SC **Department of Chemistry, University of Georgia, Athens, GA ***Department of Chemistry, University of South Carolina, Columbia, SC

\section{ABSTRACT}

Nuclear Magnetic Resonance (NMR) investigations on the Oak Ridge National Laboratory process for sol-gel synthesis of microspherical nuclear fuel $\left(\mathrm{UO}_{2}\right)$, has been extremely useful in sorting out the chemical mechanism in the sol-gel steps. ${ }^{13} \mathrm{C},{ }^{15} \mathrm{~N}$, and ${ }^{1} \mathrm{H}$ NMR studies on the HMTA gelation agent (Hexamethylene teramine, $\mathrm{C}_{6} \mathrm{H}_{12} \mathrm{~N}_{4}$ ) has revealed near quantitative stability of this adamantane-like compound in the sol-gel process, contrary to its historical role as an ammonia source for gelation from the worldwide tectmical literature. ${ }^{17} \mathrm{O} N \mathrm{NR}$ of uranyl $\left(\mathrm{UO}_{2}{ }^{++}\right)$ hydrolysis fragments produced in colloidal sols has revealed the selective formation of a uranyl trimer, $\left[\left(\mathrm{UO}_{2}\right)_{3}\left(\mu_{3}-\mathrm{O}\right)\left(\mu_{2}-\mathrm{OH}\right)_{3}\right]^{+}$, induced by basic hydrolysis with the HMTA gelation agent. Spectroscopic results will be presented to illustrate that trimer condensation occurs during sol-gel processing leading to layered polyanionic hydrous uranium oxides in which HMTAH+ is occluded as an "intercalation" cation. Subsequent sol-ge! processing of microspheres by ammonia washing results in in situ ion exchange and formation of a layered hydrous ammonium uranate with a proposed siructural formula of $\left(\mathrm{NH}_{4}\right)_{2}\left[\left(\mathrm{UO}_{2}\right)_{8} \mathrm{O}_{4}(\mathrm{OH})_{10}\right] \cdot 8 \mathrm{H}_{2} \mathrm{O}$. This compound is the precursor to sintered $\mathrm{UO}_{2}$ ceramic livel. 


\section{INTRODICTION}

Beginning in the late 1950 s, sol-gel processes were developed for the preparation of nuclear reactor fuels of $\mathrm{U}, \mathrm{Th}$, and $\mathrm{Pu}$ in the form of microspheres required for high-temperature, gascooled reactors. These fuels are commonly coated with pyrolytic carbon or other ceramics to serve as "pressure vessels" to contain fission products. The sol-gel processes for nuclear fuel were developed at Oak Ridge National Laboratory (ORNL) [1a] and were based on the gelation of colloidal sols by "internal" gelation methods previously developed for nuclear fuel synthesis in the Netherlands [2a]. In this process (Figure 1), hexamethylene tetramine (HMTA) is mixed at about $0^{\circ} \mathrm{C}$, in the presence of urea, with a uranyl nitrate solution causing hydrolysis of the uranyl cation to a hydrous uranium oxide network. HMTA functions as a weak base for hydrolysis and is also assumed to decompose to ammonia and formaldehyde. Ammonia is assumed to be produced insitu or "internally" during the gelation process and is assumed to be the key component causing gelation of the hydrous uranium oxide. All of these steps are conducted in equipment (i.e., cannulae) to form spherical drops (Figure 2) [2b] which are converted to gelatinous microspheres by suspension in a hot organic liquid (i.e., trichloroethylene). The bydrous uranium oxide in microspherical form is eventually convened to ceramic UO2 by sintering.

This paper is concerned with the use of spectroscopic probes (i.e., NMR, FTIR, SEM, TEM XRPD) to sort out the mechanism of the chemical reaction sequence during the sol-gel processing of urany! compositions. 


\section{EXPERIMENTAL}

The rate of hydrolysis of HMTA was monitored by ${ }^{13} \mathrm{C}$ NMR and ion chromatography as a function of $\mathrm{pH}$, temperature, urea and uranyl concentration. ${ }^{15} \mathrm{~N}$ and ${ }^{1} \mathrm{H}$ NMR were utilized to provide structural information on hydrolysis products. Uranyl gels were prepared by methods published by the ORNL [1b]. ${ }^{17} \mathrm{O}$ NMR was utilized to monitor the hydrolysis fragments of the uranyl cation with ${ }^{17} \mathrm{O}$ exchange with labeled water induced by photolysis. The details of ${ }^{17} \mathrm{O}$ labeling and NMR results are described in a companion publication [3a]. NMR spectra were obtained on Bruker instrumentation $\left({ }^{1} \mathrm{H},{ }^{13} \mathrm{C}: \mathrm{AM} 300 ;{ }^{17} \mathrm{O},{ }^{15} \mathrm{~N}: \mathrm{AM} 500\right)$ in the Chemistry Department at the University of South Carolina. Chemical shifts are reported relative to TMS for ${ }^{1} \mathrm{H}$ and ${ }^{13} \mathrm{C}$ spectra and relative to ${ }^{17} \mathrm{O}$ water referenced to an external $\mathrm{D}_{2} \mathrm{O} / \mathrm{H}_{2} \mathrm{O}$ standard. Concentrated ( 1.0 to $3.9 \mathrm{M}$ ) aqueous stock solutions of urany! nitrate and uranyl chloride were prepared in water enriched to $51010 \% 170$ from the $0.037 \%$ natural abundance using commercial $28 \% 170$ water from ICON Services, Inc. (Summit, New Jersey). NMR peak areas were obtained by spectral integration, and were calibrated by refareace to a set of standard HMTA solutions. NMR tmperature control was obtained via heat input from a variable temperature controller in 10 $20^{\circ} \mathrm{C}$ incremental steps from ambient to permit equilibration. Calibration was obtained using the proton spectra of ethylene glycol in DMSO-d 6 and correlating the difference $(\Delta v)$ in chumical shift of the methylene and alcohol resources with TOK $=466-1.694 \Delta v$, based on Bruker procedures.

Conditions of chemica! composition, $\mathrm{pH}$ and temperature for gelatin studies were obtained from the work of Collins et. al. [1b] of ORNL, who very thoroughly demonstrated conditions for gelation of uranyl compositions in the temperature range of $62-92^{\circ} \mathrm{C}$. Collins, et. al., [1b] demonstrated in detail that variable $\mathrm{pH}$ is observed in gel synthesis but $\mathrm{pH}$ never decreased below 3.0 under a wide variety of $\mathrm{UO}_{2}{ }^{++} / \mathrm{HMTA} /$ Urea compositions. $\mathrm{pH}$ generally varied from 3.4 to 
5.2. during gelation with extremes of 3.0 to 6.0 from the Collins, et. al., [1b] work. This range is very important in quantifying HMTA stability to hydrolysis during gelation. Gelation induction periods were generally found to be $\leq 1$ minute, and, in many cases. I the order of seconds [1b]. Temperature extremes in pilot scale gelation columns at the WSRC never exceeded $85^{\circ} \mathrm{C}$ and this temperature was chosen as the upper limit for HMTA and uranyl hydrolysis/gelation studies.

Fourier Transform Infrared spectra (FTIR) were recorded with a Nicolet 20-DX Fourier Transform Interferometer after preparation of dried gels and solids in a potassium bromide matrix compressed to 10,000 psig. X-Ray powder diffraction (XRPD) patterns were recorded on a Siemans Diffrac-50() X-Ray Diffractometer using CuKd radiation and a scintillation detector. Uranium samples were handled in a completely contained Siemans apparatus. X-Ray diffraction patterns of experimental samples were compared to reference patterns using the International Centre for Diffraction Data (Swathmore, Pa.) Joint Committee on Powder Diffraction Standards (JCPDS) files for graphic pattern evaluation including phase identification and "d" spacing.

High Pressure Ion Chromatography (HPIC) of the ammonium $\left(\mathrm{NH}_{4}{ }^{+}\right)$ion produced in HMTA hydrolysis experiments was recorded on a Dionex-400) Ion Chromatograph calibrated with standard ammonium salt solutions. Scanning Electron Micrographs (SEM) of gelatinous microspheres and sintered product were recorded on a Cambridge Stereoscan-250 Scanning Electron Microscope coupled with energy dispersive $x$-ray measurements (TRACOR TN5500) for elemental composition. Sample surfaces were carbon coated by evaporation or Au/Pd coated using a sputer coating technique. Transmission Electron Micrographs (TEM) of colloidal uranyl sols and viscous uranyl gels, produced after HMTA addition, were recorded on a Philips EM-400T Analytical Electron Microscope at 120,(0)(0) kev beam energy. Ten microliters of a $10^{6 / 1}$ diluent of 
the uranyl sol or gel were placed on a carbon substrate in a $3 \mathrm{~mm}$ diameter grid for TEM measurements.

\section{RESULTS AND DISCUSSION}

HMTA $\left(\mathrm{C}_{6} \mathrm{H}_{12} \mathrm{~N}_{4}\right)$ is a highly symmetric tertiary amine with an adamantane-like configuration $(1,3,5,7$ tetraazaadamantane). The carbon atoms and nitrogen atoms are all equivalent, with a $\mathrm{C}-\mathrm{N}$ distance of $1.44 \mathrm{~A}^{\circ}$ (bond order $1 .(0)$ ) and the four nitrogen atoms at the vertices of a tetrahedron. Electron diffraction studies $[4]$ (gas phase, $200^{\circ} \mathrm{C}$ ) confirm the molecular symmetry to be $T_{d}$ and measure the $\mathrm{C}-\mathrm{N}-\mathrm{C}$ and $\mathrm{N}-\mathrm{C}-\mathrm{N}$ bond angles to be $109.5 \pm 1^{\circ}$, the tetrahedral bond angle. A $0.2 \mathrm{M}$ aqueous solution of HMTA exhibits a pH of 8.4, illustrating that HMTA is a weak tertiary amine base in aqueous media. Each nitrogen atom, at the vertices of a tetrahedron, possesses a lone pair of electrons capable of coordination with metals, protons, or water. Equilibrium constants for protonation of HMTA have been measured by potentiometric titration [5] and nuclear magnetic resonance [6] and $\mathrm{pK}_{\mathrm{a}}$ values found to be $\sim 5.0$, a basicity similar to pyridine. British workers [6] found HMTA to be nearly completely monoprotonated in dilute acid solution by NMR which also showed diprotonation to be small $\left(\mathrm{pK}_{\mathrm{a}, 2}=-1.7\right)$.

${ }^{1} \mathrm{H}$ and ${ }^{13} \mathrm{C}$ NMR of HMTA Solutions and Gels

The proton NMR spectra of HMTA for a uranium gel-forming system was first reported by Soviet workers in the Russian Journal of Inorganic Chemistry 17] for the uranyl (VI) nitrate/HMTA/urea/water system. The Soviet workers report "the formation of a gel probably 
proceeds via hydrolysis of uranyl ions with the subsequent formation throughout the solution of a hydrogen bonded skeleton through hydroxyl bridges". Uranyl hydrolysis occurred due to the increase in solution pH resulting from HMTA protonation. The Soviets also reported no evidence for the formation of ammonia or formaldehyde due to HMTA decomposition during uranyl gel synthesis by ${ }^{1} \mathrm{H}$ NMR monitoring. Our results are consistent with Soviet [7] and British [6] reports. The ${ }^{1} \mathrm{H}$ NMR spectrum of $3 \mathrm{M}$ HMTA in $90 \% \mathrm{H}_{2} \mathrm{O} / 10 \% \mathrm{D}_{2} \mathrm{O}$ at $25^{\circ} \mathrm{C}$ and $\mathrm{pH} 8.4$ shows a single methylene proton resonance at $4.65 \mathrm{ppm}$ and a water resonance at $4.85 \mathrm{ppm}$. The HMTA methylene resonance progressively shifts to lower field as $\mathrm{pH}$ is decreased and is observed at 4.9 $\mathrm{ppm}$ at $\mathrm{pH} 2.0$ for the monoprotonated species. The resonance was monitored for 1.25 hours at pH 2.0 and $52^{\circ} \mathrm{C}$ (gel conditions) and was observed to decrease $\sim 5 \%$, implying the $\mathrm{C}_{6} \mathrm{H}_{12} \mathrm{~N}_{4} \mathrm{H}^{+}$ form is highly stable. In a uranyl gel, the HMTA and water resonances eventually coallese to an average broad signal at 4.80 ppm-similar to Soviet observations [7].

${ }^{13} \mathrm{C}$ NMR was found to be much more instructive of structural modifications during hydrolysis and gelation. Figure $3 \mathrm{a}$ is the ${ }^{13} \mathrm{C}$ NMR of a $3 \mathrm{M} \mathrm{HMTA}$ solution at $\mathrm{pH} 8.9$ and $75^{\circ} \mathrm{C}$. The nonprotonated form exhibits a single resonance at $75.6 \mathrm{ppm}$-confirming the chemical and magnetic equivalence of the six methylene carbon atoms of the adamantane-like structure (inset). Area integration of the signal over one hour showed no change $( \pm 1 \%)$ and no new resonancesimplying complete stability. The ${ }^{13} \mathrm{C}$ spectrum was monitored as a function of pit, time, temperature, urea, and uranium concentration to test for hydrolytic instability under gelation conditions. Some observations are also presented in Figure 3 to illustrate the trends. At $85^{\circ} \mathrm{C}$ and pH 3.2, three new resonances appear at 46.4,73.6, and $83.4 \mathrm{ppm}$ and increase with time (stack spectra) in an approximate ratio of $1 / 2 / 3$. HMTA is converting slowly to a highly symmetric new product whose carbon framework is similar to HMTA. The weak 46.4 ppm resonance is consistent in chemical shift with a carbon adjacent to a primary amine (i.e., $\mathrm{CH}_{2}-\mathrm{NH}_{2}$ ) and the latter resonances reflect a carbon environment similar in structure to HMTA. The ${ }^{13} \mathrm{C}$ NMR of a 
uranyl gel structure (Figure 3d) containing urea and HMTA is significantly broadened due to increased gel viscosity but the same pattern is discernable. The sol-to-gel transition can be observed in a magnetic field. Formaldehyde or polyoxy methylene oligomer resonances of aqueous formaldehyde polymers, expected at $\sim 90 \mathrm{ppm}[8 \mathrm{a}$ ], were never observed in the $\mathrm{pH}$ range of 2.0 to 8.9 even at high gelation temperatures. This was confirmed by recording the ${ }^{13} \mathrm{C} \mathrm{NMR}$ spectrum of $30 \%$ aqueous formaldehyde which clearly showed a distinct but very complex pattern in the low field ( $-90 \mathrm{ppm})$ region.

Integration of the observed HMTA ${ }^{13} \mathrm{C}$. resonances was recorded with time and the results are shown in Figure $4 \mathrm{a}$. The half-life for HMTA decomposition by hydrolysis is $\sim 70$ minutes at $85^{\circ} \mathrm{C}, \mathrm{pH} 3.2$ and is independent of the presence of urea and uranium (zero order). The reaction or residence time for sol-gel synthesis of microspherical particles is is known to be $\leq 3$ minutes based upon ORNL experience [1a, b]. Clearly, HMTA under these conditions is nearly quantitatively stable based upon NMR signal integration. Ammonia generation during HMTA hydrolysis was confirmed by High Pressure Ion Chromatography measurements of the $\mathrm{NH}_{4}^{+}$cation and ${ }^{15} \mathrm{~N}$ NMR measurements. Under gelation conditions, ammonia generation never exceed one equivalent of ammonia per mole of HMTA. Complete decomposition of HMTA would require four moles via, $\mathrm{C}_{6} \mathrm{H}_{12} \mathrm{~N}_{4}+6 \mathrm{H}_{2} \mathrm{O} \rightarrow 4 \mathrm{NH}_{3}+6 \mathrm{CH}_{2} \mathrm{O}$, the reaction frequently cited in the sol-gel literature $[1,2]$ as occuring in the internal gelation process. The hydrolysis fragment monitored by ${ }^{13} \mathrm{C}$ NMR was confirmed to be tris (hydroxymethyl) hexahydrotriazine through the intrmediacy of an amino-methyl derivative (Figure $4 b$ ).

The observation of triazine derivatives from HMTA hydrolysis is consistent with the British [6] and Bangalore Research Institute [8a] reports on the mechanism of the HMTA synthesis reaction and structural work on HMTAH ${ }^{+} \mathrm{Br}-$ by the Chinese University of Hong Kong [8b] in which tris (hydroxymethyl) hexahydrotriazine was suggested as a plausible hydrolysis product due to the measured distortion of the adamantane-like cage structure upon protonation. The distortion of 
$\mathrm{HMTAH}^{+}$was confirmed by molecular mechanics calculations using PCMODEL (Serena Software, Bloomington, IN) with excellent agreement in calculated geometry relative to the Chinese work [8b]. The formation of the hydroxy/triazine derivative liberates one mole of ammonia [Figure 4b] consistent with HPIC measurements. The details of the mechanism of this reaction supported by ${ }^{1} \mathrm{H}$ and ${ }^{13} \mathrm{C}$ NMR measurements are summarized in companion publications [8c]. Under conditions of interest to the ORNL flowsheet, the gelation agent HMTA is $98 \%$ stable in the gelation process and is most likely playing a structural role in gel formation. This proposal was confirmed by monitoring the hydrolysis fragments of the uranyl cation by ${ }^{17} \mathrm{O}$ NMR. Of practical significance, stable HMTA was found to contribute residues of carbon in sintered $\mathrm{UO}_{2}$ if not properly monitored or leached during gel microsphere washing in the ORNL flowsheet. In addition, a mechanism for microsphere bursting or cracking associated with volatile products from high temperature HMTA thermolysis can occur if HMTA is retained in the microspheres during sintering.

\section{${ }^{17} \mathrm{O}$ NMR of Uranyl Hydrolysis Fragments Under Gelation Conditions}

${ }^{17}$ O NMR was utilized to monitor uranyl speciation under sol-gel conditions [3a]. Specifically, in the ORNL flowsheet, "Acid Deficient Uranyl Nitrate" (ADUN) is prepared as the "sol" and pH adjustment with HMTA is conducted to prepare the feed for the gelation step under microsphere forming conditions (Figure 1). The composition of ADUN has not been elucidated. Prior ${ }^{17} \mathrm{O}$ NMR work by Japanese [9] and Soviet [10] researchers had illustrated the utility of ${ }^{17} \mathrm{O}$ NMR in characterization of uranyl hydrolysis products as a function of $\mathrm{pH}$, temperature, and ligand complexation by monitoring the ${ }^{17} \mathrm{O}$ resonance of the axial uranyl oxygen. This prior work $[9,10]$ was used to assist in making assignments of uranyl hydrolysis oligomers based upon chemical shift measurements and dynamic modification of observed resonances as a function of $\mathrm{pH}$ 
adjustment. $17 \mathrm{O}$ has a spin of $5 / 2$ and an associated nuclear guadrapole moment [3b] which may induce line broadening, particularly in viscous gels.

Figure 5a illustrates the ${ }^{17}$ O NMR resonances of the axial uranyl oxygens for synthetic ADUN compositions induced by extraction of the counter ion by tri-n-decyl amine in xylene-a known method for synthesis of a colloidal sol [1,2]. The spectra clearly show the monomer, $\mathrm{UO}_{2} \mathrm{OH}^{+}$; the dimer $\left(\mathrm{UO}_{2}\right)_{2}(\mathrm{OH})_{2}^{++}$, and the trimer, $\left(\mathrm{UO}_{2}\right)_{3}(\mathrm{OH})_{5}^{+}$, at approximately $1119.4,1121.2$, and $1127.7 \mathrm{ppm}$ respectively $[3,9]$. When a tertiary amine base, such as HMTA, is used to induce hydrolysis (Figure 5b) the spectra are similar but greatly modified with preferential formation of trimer $(95 \%)$ in the presence of the gelation agent. These results also provide a clue for the role of the urea in the ORNL flowsheet. Urea complexes, probably by oxygen loan pair donation via the carbonyl functionality, to the equitorial coordination sphere of the uranyl oligomers [11]. This was observed as minor downfield shifts of all the resonances, as reported by Japanese workers $[9,11]$, due to increasing base strength of the equatorial ligands of the uranyl ion. Urea promotes solution stability of the uranyl hydrolysis fragments and prevents premature precipitation of the "sol" oligomers upon addition of a base-such as HMTA. Hence, urea and HMTA are both integral in the preparation of a stable uranyl gel:

- Urea promotes colloidal uranyl oligomer stability by ligand coordination and prevents premature uranium precipitation,

- HMTA provides the $\mathrm{pH}$ adjustment necessary for a gel network to form, induces uranyl trimer formation, and probably promotes the formation of a stable gel network by intra-molecular and inter-molecular hydrogen bonding. 


\section{Evidence for HMTA as a Promoter of Hydrogen Bonding During Gelation}

A schematic of the proposed molecular complex of the uranyl trimer, urea, and HMTA is shown in Figure 6. Each uranyl group is in pentagonal bypyramidal coordination [12] with the equitorial coordination number satisfied by urea or water complexation as a ligand $(L)$. The triad of uranyl groups is stabilized by a $\mu_{3}$-oxo bridge [12] and $\mu_{2}-\mathrm{OH}$ bridging. Intra-molecular hydrogen bonding with HMTA occurs via hydroxyl bridges with proton donation to a lone pair nitrogen of HMTA. The other nitrogen lone pairs can participate in inter-molecular hydrogen bonding establishing a gel network. Further support for this representation was found by observation of the Fourier Transform Infrared Spectra (FTIR) of HMTA in the gel structure (Figure 7). HMTA exists in the gel structure as $\mathrm{HMTAH}^{+}$characterized by the splitting of degenerate $\mathrm{C}-\mathrm{N}$ vibrations $\left(1030 \mathrm{~cm}^{-1}\right)$ due to nitrogen protonation and distortion of the cage structure [8b] causing a change of molecular symmetry from $T_{d}$ to $C_{3 v}$. In addition, a complex pattern around $2500 \mathrm{~cm}^{-1}$ is characteristic of the quaternary ammonium species. This gel form was further substantiated by FTIR comparison with the simple hydrochloride salt of HMTA (HMTA - HCL). The sol to gel transition induced by HMTA addition can also be observed by Transmission Electron Microscopy (TEM) as shown in Figu e 8. The sol consists of 30 \& particles which "bridge" to form "strings" of hydrous uranium oxide which further coallese or aggregate in the gel phase. The TEM patterns are a very interesting example of change in fractal geometry during the sol to gel transition.

Evidence for the participation of HMTA in solvent interactions via hydrogen bonding giving rise to unique properties and structures have been shown by a number of diverse studies [13-15]. Syracuse University researchers $|13 \mathrm{a}|$ studied solution hydrogen bonding and protonation of polycyclic polyamines, including $\mathrm{HMTA}$ by ${ }^{13} \mathrm{C}$ and ${ }^{15} \mathrm{~N}$ NMR relaxation measurements and claimed that the slower rate of rotation of HMTA in aqueous solution was associated with greater "frictional" interactions of HMTA with water because of the number of nitrogen atoms capable of 
solvent interaction. They estimated the H-bond tistance to be $1.9 \AA$, comparable to other O-H...N systems. Other NMR measurements [13b] showed HMTA to be much more restricted in its motion in solution than its structural analogue-adamantane-because of hydrogen bonding with the solvent.

Aqueous solutions of HMTA are known to exhibit unique properties associated with solute-solvent interactions [14] and to form fully-hydiogen-bonded molecular crystals [15]. For example, HMTA forms a hexahydrate with water at $0^{\circ} \mathrm{C}$ whose crystal structure has been shown [15a] to be a novel type of clathrate structure characterized by hydrogen-bonding interaction between the host (water) and guest (HMTA) species. The watur molecules form a hydrogen-bonded framework consisting of columns of $\left(\mathrm{H}_{2} \mathrm{O}\right)_{6}$ rings cross linked to one another. Each HMTA molecule is located in a cage within the clathrate framework, and is hydrogen bonded to the water lattice through three of its four nitrogen atoms. Each HMTA molecule is surrounded ty eight $\left(\mathrm{H}_{2} \mathrm{O}\right)_{6}$ rings and is hydrogen bonded to three rings in a "batlike" cavity configuration. Three nitrogen atoms of HMTA are hydrogen-bond acceptors while the fourth nitrogen atom is at van der waals distances from neighboring water and not involved in hydrogen bonding. HMTA is known to form stable hydrates with a variety of metal ions (for example, $\mathrm{MX}_{2} \cdot \mathrm{nH}_{2} \mathrm{O} \cdot 2 \mathrm{HMTA}$, where $\mathrm{M}$ $=\mathrm{Ca} . \mathrm{Mg}, \mathrm{Co}$, and $\mathrm{Ni}: \mathrm{X}=\mathrm{Br}, \mathrm{Cl}$ and $\mathrm{n}=7-10)$. The structure of $\mathrm{CaBr}_{2} \cdot 1 . \mathrm{H}_{2} \mathrm{O} \cdot 2 \mathrm{HMTA}$ has been fully determined by single crystal X-ray diffraction $[15 b, c]$. Calcium is octahedrally coordinated to six water molecules and three nitrogen atoms of each HMTA molecule are linked by N...H...O hydrogen bonds to the octahedrally coordinated water of three different calcium ions-generating a two dimentional network. The layers are linked together by chains of hydrogen bonds between water and the fourth HMTA nitrogen atom. The structure is fully hydrogen bonded. The three-fold increase in relative viscosity of $3 \mathrm{M} \mathrm{HMTA}$ in aqueous solutions $[149, \mathrm{~b}]$, along with: increased density $[14 \mathrm{a}, \mathrm{b} \mid$, critical micelle concentration of colloidal electrolytes [14a] and conductance measuremernts $[1$ tc have been interpreted by I HTA functioning as a "water structure reinforcing agert" through hydrogen thonding.

Msin:03: 
These observations add support to our hypothesis that the role of stable HMTA in the formation of stable uranyl gels is via a hydrogen bonding mechanism promoting a three-dimentional gel network [Figure 6].

\section{The Structure of the Hydrous Uranium Oxide Precursors to Sintered $\mathrm{UO}_{2}$}

In the ORNL flowsheet (Figure 1), gelatinous microspheres are washed with $0.5 \mathrm{M} \mathrm{NH} 4 \mathrm{OH}$, which is assumed to leach impurities such as urea, formaldeh, de and nitrate. The resulting $\mathrm{pH}$ increase also causes additional uranyl trimer condensation to hydrous uranium oxide polymers. The nature of the polymer in the post-washed gel formed in the internal gelation process has been studied by Lloyd, et. ai., [16] under various chemical conditions and was found to be consistent with a complex composition of $\mathrm{UO}_{3} \bullet 2 \mathrm{H}_{2} \mathrm{O}, 4 \mathrm{UO}_{3} \bullet \mathrm{NH}_{3} \bullet 7 \mathrm{H}_{2} \mathrm{O}$ and $2 \mathrm{UO}_{3} \bullet \mathrm{NH}_{3}, \bullet 3 \mathrm{H}_{2} \mathrm{O}$ based upon X-ray diffraction analysis. Our results compliment the Lloyd, et.al., interpretation and provide additional insight on the structure of the hydrous uranium oxide polymer and the mechanism of the washing step.

The ammonia washing treatment has been shown to be an ion exchange step in which the occluded HMTA molecule in protonated form $\left(\mathrm{HMTAH}^{+}\right)$is exchanged for the ammonium cation. At the same time, further condensation of the uranyl trimer occurs to polyanionic hydrous uranium oxide in a layered configuration. $\mathrm{HMTAH}^{+}$and/or $\mathrm{NH}_{4}{ }^{+}$are incorporated as "intercalation" cations to balance the negative charge of the hydrous uranium oxide layer. This was confirmed by XRPD and FTIR measurements on uranyl gels and synthetic compositions. In addition, a very interesting structural analogue in the uranium mineral family [17] has been extremely useful in providing a structural interpretation of the hydrous uranium oxide network. 
Figure $9 \mathrm{a}$ is an XRPD pattern of a synthetic sample from ammonia treatment of a uranyl solution at $\mathrm{pH}$ 4.5. The yellow crystalline compound had an approximate stoichiometry of $4 \mathrm{UO}_{3} \bullet \mathrm{NH}_{3} \bullet 7$ $\mathrm{H}_{2} \mathrm{O}$ and is in good agreement with the literature pattern of Garner [18]. XRPD on washed gel samples gave broader, more amorphous, patterns but were similar to Figure 9a. The Garner composition was classified in the urthorombic system as a layered structure with a 002 or basal reflection of $7.55 \AA$, the distance between the layers, but the atomic arrangements were undefined. Recently, complete crystal structures of a series of hydrous uranium oxide minerals were published by workers from the University of Maryland and the Smithsonian Institute [17]. A XRPD pattern comparison with our synthetic ammonium, gel-like, derivative is shown in Figure $9 \mathrm{~b}$ for the natural mineral Billietite ( $\mathrm{BaO} \cdot 6 \mathrm{UO}_{3} \cdot 11 \mathrm{H}_{2} \mathrm{O}$ ), whose atomic arrangements (Figure 9c) are shown from the Pagoaga, et. a1., work [17]. The principal "d" spacings are compared in Table I. Billietite is a naturally cccuring barium-containing hydrous uranium oxide polymer in which the uranyl moity is retained in $\mu_{3}$-oxo bridging in an oxygen layer and the barium cations maintain the layer dimensions $(7.50 \AA$. ) along with interstitial water in hydrogen bonding. Hence, barium is the "intercalation" cation between hydrous uranium oxide layers. Billietite contains quasi-linear $\left(\mathrm{UO}_{2}\right)^{+2}$ groups coordinated by five oxygen atoms to form a pentagonal bipyramid of $\left[\left(\mathrm{UO}_{2}\right) \mathrm{O}_{2}(\mathrm{OH}) 3\right]$. This polyhedron shares pentagonal edges to form sheets of $\left.[\mathrm{UO} 2)_{6} \mathrm{O}_{4}(\mathrm{OH})_{6}\right]_{n}^{-2 \eta}$. 0.20 , which are parallel and are bonded together by intercalation barium cations and water molecules. 
Table I. X-Ray Diffaction Powder Patterns of Hydrous Uranium Oxide Minerals and Synthetic Gel-Like Product: Summary of Principal "d" Spacings

\section{Poly Oxy Uranate Structures}

Summary of Princtple "o" Spacings

$24 \mathrm{Q}_{2} \cdot 2 \mathrm{NHH}_{2} \cdot 14 \mathrm{H}_{2} \mathrm{\Omega}$

$7.55 \AA 002 / 100 \%$

$3.77 \AA 0004 / 60 \%$

$3.54 \AA \quad 130 / 80 \%$

$3.20 \AA \quad 132 / 80 \%$

Orthorhombic

$$
\begin{aligned}
& a=7.16 \AA \\
& b=12.21 \\
& c=15.02 \\
& \alpha, \beta, \delta=90^{\circ}
\end{aligned}
$$

Billiettite $\mathrm{BaO} \cdot 6 \mathrm{YO}_{2} \cdot 11 \mathrm{H}_{2} \mathrm{O}$

$$
\begin{aligned}
& 7.46 \AA \\
& 3.76 \AA \\
& 3.50 \AA \\
& 3.17 \AA
\end{aligned}
$$

Becquerellte $\mathrm{CaO} \cdot 6 \mathrm{NQ}_{2} \cdot 11 \mathrm{H}_{2} \mathrm{O}$

$$
\begin{aligned}
& 7.54 \AA \\
& 3.74 \AA \\
& 3.55 \AA \\
& 3.21 \AA
\end{aligned}
$$

Fourmarterte $\mathrm{BbO} \cdot 4 \mathrm{UO}_{2} \cdot 5 \mathrm{H}_{2} \mathrm{O}$

$7.14 \AA$

$$
3.54 \AA
$$$$
3.16 \AA
$$

Vandendrlesschelte $\mathrm{PhO} \cdot 7 \mathrm{UO}_{2} \cdot 12 \mathrm{H}_{2} \mathrm{O}$

$$
7.22 \AA
$$

$3.50 \AA$

$3.15 \AA$
Orthorhomblc

$$
\begin{aligned}
& a=13.98 \AA \\
& b=12.08 \AA \\
& c=15.06 \AA \\
& \alpha, \beta, \delta=90^{\circ}
\end{aligned}
$$

Orthorhomble

$$
\begin{aligned}
& a=13.92 \AA \\
& b=12.45 \AA \\
& c=15.09 \AA \\
& \alpha, \beta, \delta=90^{\circ}
\end{aligned}
$$

Orthorhombic

$$
\begin{aligned}
& a=13.99 \AA \\
& b=16.40 \\
& c=14.29 \\
& \alpha \beta . \delta=90^{\circ}
\end{aligned}
$$

$7.50 \AA$
$7.14 \AA$
Orthonomblc

$$
\begin{aligned}
& a=14.12 \AA \\
& b=16.80 \\
& c=14.72 \\
& \alpha \beta, \delta=90^{\circ}
\end{aligned}
$$

\section{Layer or
Basal \\ Spacing}

$7.50 \AA ̊$

$7.35 \AA ̊$ 
The Pagoago, et.al., work [17] confirms the predictions of Evans [19] that hydrous uranium oxides would show mainly pentagonal coordination around the uranyl ion-allowing the equitorial oxygen atoms to remain in a plane orthogonal to the uranyl species without crowding. The uranium-oxygen sheet found in the uranyl oxide hydrate minerals is similar in structure to the sheets in $\alpha$ and $\beta-U_{3} O_{8}$ [17], In $\alpha-U_{3} O_{8}$, each of the quasi-uranyl ions is coordinated to five oxygen atoms in the wranyl equitorial plane - a pentagonal bipyramidal array. In $\beta-U_{3} \mathrm{O}_{8}$, two of the quasi-uranyl ions, are equitorially five coordinate, but one uranyl ion is only four coordinate equitorially and hence exhibits tetragonal bipyramid or "distorted" octahedral symmetry. Billietite is similar to the $\alpha \mathrm{U}_{3} \mathrm{O}_{8}$ structure but is distorted towards $\beta-\mathrm{U}_{3} \mathrm{O}_{8}$ with coordination around two uranyl ions in the uranium-oxygen sheet being almost fourfold [17]. $\mathrm{U}_{3} \mathrm{O}_{8}$ is also a significant structure and composition in nuclear fuel synthesis.

It is instructive to note that the uranyl equitorial coordination number of five, and the oxygen/hydroxy bridging framework of the uranyl trimer of Aberg [12b] and the uranyl tetramer of Aberg [12c] and Perrin, et.al., [12d] exhibit the pentagonal bipyramidal configurations and oxygen bonding patterns of the infinite chain hydrous uranium oxide minerals [17]. It is our contention that the uranyl trimer, as observed by $170 \mathrm{NMR}$, is in fact the precursor to condensation of an infinite chain polymer of uranium-induced by basic hydrolysis with $\mathrm{HMTAH}^{+}$or $\mathrm{NH}^{+}$. The remarkable agreement between synthetic and natural mineral patterns, (Figure 9b), both in "d" spacing and intensities, provides additional structural information. For a series of natural uranium minerals, including Billietite, structural formulae have been calculated from empirical formulae and $x$-ray patterns (Table II) 117|. We have proposed a structural formula for the synthetic ammonium derivative to be: $\left(\mathrm{NH}_{4}\right)_{2}\left[\left(\mathrm{UO}_{2}\right)_{8} \mathrm{O}_{4}(\mathrm{OH})_{10}\right] \cdot 8 \mathrm{H}_{2} \mathrm{O}$, a layered hydrous uranium oxide with ammonium ions as intercalation cations. The intercalation of ammonium and alkyl-ammonium cations $\left(\mathrm{HMTAH}^{+}\right)$(Figure 9d) proved to be a general phenomenon of hydrous uranium oxide condensation. Seven alkyl ammonium derivatives have been prepared and shown to be 
Table II. Hydrous Uranium Oxide Minerals and Synthetic Compositions: Empirical and Structural Formulae

\section{Uranium Mineral Structures and Ammonium Poly Oxy Uranates}

Mineral

Becquerelite

Billietite

Protasite

de Margnac II

Fourmarierite

Sayrite

Curite

Vandendriesscheite

Ammonium

Poly Oxy Uranate
$\mathrm{CaO} \cdot 6 \mathrm{UO}_{3} \cdot 11 \mathrm{H}_{2} \mathrm{O}$

$\mathrm{BaO} \cdot 6 \mathrm{UO}_{3} \cdot 11 \mathrm{H}_{2} \mathrm{O}$

$\mathrm{BaO} \cdot 3 \mathrm{UO}_{3} \cdot 4 \mathrm{H}_{2} \mathrm{O}$

$\mathrm{SrO} \cdot 6 \mathrm{UO}_{3} \cdot 1 \mathrm{OH}_{2} \mathrm{O}$

$\mathrm{PbO} \cdot 4 \mathrm{UO}_{3} \cdot 5 \mathrm{H}_{2} \mathrm{O}$

$2 \mathrm{PbO} \cdot 5 \mathrm{UO}_{3} \cdot 5 \mathrm{H}_{2} \mathrm{O}$

$3 \mathrm{PbO} \cdot 8 \mathrm{UO}_{3} \cdot 5 \mathrm{H}_{2} \mathrm{O}$

$\mathrm{PbO} \cdot 7 \mathrm{UO}_{3} \cdot 12 \mathrm{H}_{2} \mathrm{O}$

$2 \mathrm{NH}_{3} \cdot 8 \mathrm{UO}_{3} \cdot 14 \mathrm{H}_{2} \mathrm{O}$
Structural

Formula
$\mathrm{Ca}\left[\left(\mathrm{UO}_{2}\right)_{6} \mathrm{O}_{4}(\mathrm{OH})_{6}\right] \cdot 8 \mathrm{H}_{2} \mathrm{O}$

$\mathrm{Ba}\left[\left(\mathrm{UO}_{2}\right)_{6} \mathrm{O}_{4}\left(\mathrm{OH}_{6}\right] \cdot 4 \mathrm{H}_{2} \mathrm{O}\right.$

$\mathrm{Ba}\left[\left(\mathrm{UO}_{2}\right)_{3} \mathrm{O}_{3}(\mathrm{OH})_{2}\right] \cdot 3 \mathrm{H}_{2} \mathrm{O}$

$\mathrm{Sr}\left[\left(\mathrm{UO}_{2}\right)_{6} \mathrm{O}_{4}(\mathrm{OH})_{6}\right] \cdot 7 \mathrm{H}_{2} \mathrm{O}$

$\mathrm{Pb}\left[\left(\mathrm{UO}_{2}\right)_{4} \mathrm{O}_{3}(\mathrm{OH})_{4}\right] \cdot 4 \mathrm{H}_{2} \mathrm{O}$

$\mathrm{Pb}_{2}\left[\left(\mathrm{UO}_{2}\right)_{5} \mathrm{O}_{6}(\mathrm{OH})_{2}\right] \cdot 4 \mathrm{H}_{2} \mathrm{O}$

$\mathrm{Pb}_{3}\left[\left(\mathrm{UO}_{2}\right)_{8} \mathrm{O}_{8}(\mathrm{OH})_{6}\right] \cdot 3 \mathrm{H}_{2} \mathrm{O}$
Cystal

Class

Orthortiombic

Orthorhombic

Monoclinic

Orthorhombic

Orthorhombic

Monoclinic

Orthorhombic

Orthorhombic

$\left(\mathrm{NH}_{4}\right)_{2}\left[\left(\mathrm{UO}_{2}\right)_{8} \mathrm{O}_{4}(\mathrm{OH})_{10}\right] \cdot 8 \mathrm{H}_{2} \mathrm{O}^{*}$ Orthorhombic
Basal

Spacing
$7.50 \AA$
$7.50 \AA$
$7.06 \AA$
$7.08 \AA$

$7.14 \AA$

$7.25 \AA$

$8.40 \AA$

$7.35 \AA$

"Proposed 
isostructural by XRPD and solid state ${ }^{17} \mathrm{O}$ NMR. The intercalation cations can be osbserved and structurally characterized by FTIR and TGA/Mass Spectroscopy.

The basal or layer dimension is controlled by the size of the intercalation cation, similar to the known intercalates of ilydrogen uranyl phosphate [20]. All are precursors to ceramic nuclear fuel $\left(\mathrm{UO}_{2}\right)$ and exhibit ion exchange properties. Structural characterization and properties will be described in future publications [21-23].

\section{SEM Observations on Synthetic Hydrous Uranium Oxide Microspheres}

A final example of the interesting morphologies produced via the sol-gel processing sequence to form microspheres of hydrous uranium oxide is shown in Figure 10 using Scanning Electron Microscopy (SEM). These 300 micron sheres were produced in pilot-scale equipment at the Westinghouse Savannah River Site. As the SEM magnification is increased, imperfections and shape irregularities become apparent, believed to be due to dynamic collisions of particles in the sphere forming column. SEM proved useful in monitoring microsphere morphology as synthesis conditions were varied. Closer inspections of the microsphere surface reveals a highly roughened or "sandpaper" texture which is quite revealing at the highest magnification $(4,000 \mathrm{X})$. The surface consists of an immense cluster of platelets whose individual dimensions average $\sim 4$ microns by 0.5 micron. Energy dispersive X-ray measurements and XRPD revealed the surface structure to be synthetic meta-schoepite $\left(\mathrm{UO}_{3} \cdot 2 \mathrm{H}_{2} \mathrm{O}\right)$, and a layered hydrous uranium oxide [16]. Estimates of surface area exceed $700 \mathrm{~m}^{2} / \mathrm{g}$. Hence, under some synthetic conditions, the unique layered uranium-oxygen network can be observed on the surface of microspheres produced via the very versatile uranium sol-gel process.

\section{CONCLUSIONS}

HMTA is stable in the internal gelation process for urania microsphere synthesis as the protonated cation and plays a structural role in gel formation, probably through hydrogen bonding. The colloidal "sol" was shown io be a mixture of uranyi oligomers. "The uranyl trimer is predominent 
in the "gel" structure with urea in the uranium equitorial coordination sphere and HMTAH $^{+}$ promoting uranyl trimer formation and the gel network. The trimer condenses to a layered hydrous uranium oxide polymer in which ammonium or $\mathrm{HMTAH}^{+}$cations stabilize the layer configuration as "intercalation" cations. A structural concept of the layered configuration was obtained from natural uranium mineral analogues. The layered network serves as the structural precursor to ceramic nuclear fuel $\left(\mathrm{UO}_{2}\right)$.

\section{ACKNOWLEDGEMENTS}

This work was conducted under Contract No. DE-AC09-76SR00001 with the U.S. Department of Energy. The authors gratefully acknowledge the assistance of Prof. Andrew Streitwieser of the University of California/Berkeley Chemistry Dept. on ${ }^{1} \mathrm{H}$ and ${ }^{13} \mathrm{C}$ NMR interpretation, Dr. John Reed of the E. I. du Pont de Nemours \& Co. Biochemicals Department on initial guidance on NMR measurements, and Dr. Jack Collins of ORNL on useful literature and process insight. Coworkers of the WSRC included Mrs. Nancy Gregory, Mrs. Arlene Ray and Mr. Joel Livingston (Radiochemistry), Mrs. Joyce L. Hunter (XRPD), Mrs. Marti Finney (SEM) and Mr. Dan Steedley (TEM). Their tireless effort is gratefully acknowledged. 


\section{REFERENCES}

1. a. P. A. Hass, J. M. Begovich, A. D. Ryon and J. S. Vavruska. I \& EC Product Research and Development 19, p459 (1980)

b. J. L. Collins, M. H. Lloyd and R. L. Fellows. Radiochem. Acta 42, p121 (1987).

c. P. A. Haas Chemical Engineering Progress, p44 April (1989)

2. a. J. B. W. Kanji, A. J. Noothout, and O. Votocek. "The KEMA U(VI) Process for the Production of $\mathrm{UO}_{2}$ Microspheres", pp185-195 in "Sol-Gel Processes for Fuel Fabrication", IAEA-161, International Atomic Energy Agency, Vienna, 1974.

b. V. N. Vaidya, S. K. Muberjee, J. K. Joshi, R. V. Kamat, and D. D. Sood Journal of Nuclear Materials 148324 (1987)

3. a. R. Bruce King, C. M. King and A. R. Garber. "An ${ }^{17}$ O NMR Study of Uranyl Hydrolysis and Gelation". In the Proceedings of Better Ceramics through Chemistry IV, Materials Research Society, San Francisco, CA. April 16-21, 1990

b. W. G. Klemperer, Angew. Chem. Int. Ed. Engl. 17246 (1978)

4. P. A. Schaffer, Jr., J. Amer. Chem. Soc., 69, 1557 (1947).

5. H. Tada. Journal American Chemical Society 82, p225 (1960) 
6. P. Gulding, A. P. Cooney, and M. R. Crampton. Journal Chemical Society, Perkin Trans. II, p835 (1986).

7. A. A. Vashman, I. S. Pronin, T. V. Brylkina, and V. M. Makarov. Russ J. of Inorg. Chem., 24 (10), p1515 (1979) (Engi).

8. a. S. Narasimhan and A. S. Kumar, Indian Journal of Chemistry 24B 568 (1985)

b. T. C. M. Mak, W. K. Li and W. H. YIP, Acta Cryst. C39 134 (1983)

c. C. M. King, M. C. Thompson, A. R. Garber and A. Streitwieser, Jr. "Studies on the Mechanism of Hydrolysis of [1, 3, 5, 7] Tetra-aza adamantane", Journal American Chemical Society (to be submitted); "NMR Studies on the Role of Gelation Agents in a U(VI) Sol-Gel Process" Better Ceramic through Chemistry Sym; Matls Res Soc Proceedings San Francisco, CA, April 16-21, 1990.

9. W. S. Jung, H. Tomiyasu, and H. Fukutomi. Chem. Comm. p372 (1987).

10. V.A. Shcherbakov and L. G. Mashirov. Soviet Radiochemistry 26, p666 (1984) (Eng1).

11. W. S. Jung, H. Tomiyasu, and H. Fukutomi. Bulletin Chem. Soc. Japan 58, p938 (1985)

12. a. M. Aberg. Acta Chem. Scand. 23791 (1969)

b. M. Aberg. Acta Chem. Scand. A32, pl01 (1978).

b. M. Aberg. Acta Chem. Scand. A30, p507 (1976).

d. A. Perrin and J. Y. le Marouille, Acta Cryst.., B33 p2477 (1977).

13. a. D. J. Cralb, G. C. Levy and A. Lombardo J. Physical Chem $\underline{86} 3893$ (1982)

b. R. E. Wasylishen and B. A. Pettitt, Canadian Journal of Chemistry 55, 2564 (1977) 
14. a. G. Barone, V. Crescenzi, A. M. Liquori, and F. Quadrifoglio J. Physical Chemistry 71 $984(1967)$

b. V. Crescenzi, F. Quadrifoglio and V. Vitaglina J. Physical Chem. 712313 (1967)

c. G. Barone, V. Crescenzi, and V. Vitragliano J. Physical Chem 722588 (1968)

d. J. L. Neal and D.A.I. Goring J. Physical Chem 74658 (1970)

e. F. Quadrifoglio, V. Crescenzi, A. Cesaro, and F. Delben J. Physical Chem 753633 (1971)

15. a. T. C. W. Mak, J. Chem. Physics 432799 (1965)

b. P. De Santis, A. L. Kovacs, A. M. Liquori, L. Mazzarella J. Amer. Chem. Soc. 87:21, $4965(1965)$

c. L. Mazzarella, A. L. Kovacs, P. De Santis, and A. M. Liquori Acta Cryst. 2265 (1967)

16. M. H. Lloyd, K. Bischoff, K. Peng, H. U. Nissen and R. Wessicken. Journal Inorganic and Nuclear Chemistry 38, p1141 (1976)

17. M. K. Pagoaga, D. E. Appleman and J. E. Stewart. American Minerologist, 72 pl230 (1987)

18. W. Garner. Journal Inorganic and Nuclear Chemistry 21, p380 (1960).

19. H. T. Evans, Science 141 p154 (1963).

20. R. Pozas - Tormo, L. Moreno-Real, M. Martinez-Lara and S. Bruque - Gamez. Can. Journal Chemistry 64, p30 (1986). 
21. C. M. King, M. C. Thompson, and V. Van Brunt "New Precursors to Ceramic Nuclear Fuel: Polycyclic Polyamine Polyuranates" J. Nuclear Materials (to be submitted).

22. C. M. King, R. B. King, P. Ellis and J. A. Edwards "Solid State ${ }^{17}$ O NMR of Hydrous Uranium Oxide Alkyl Amine Intercalation Compounds" Journal American Chemical Society (to be submitted).

23. C. M. King, R. B. King, B. R. Buchanan, and A. R. Jurgenson "Structural Characterizaiton of New Intercalation Compounds of Hydrous Uranium Oxide" Inorganic Chemistry (to be submitted). 


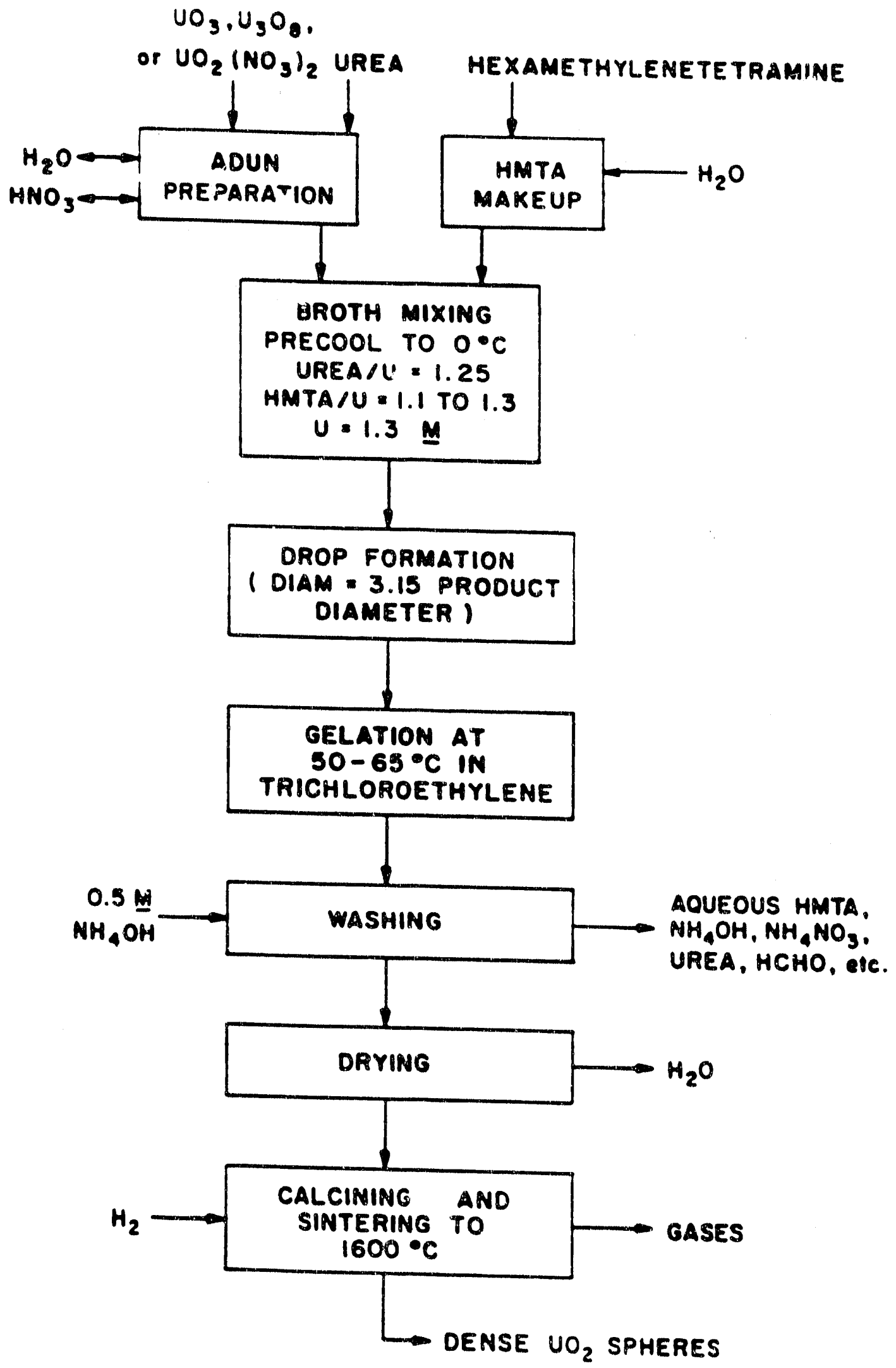

FIGURE 1. THE OAK RIDGE NATIONAL LABORATORY FLOWSHEET FOR URANIUM ( $\left.\mathrm{UO}_{2}\right)$ MICROSPHERE SYNTHESIS. 


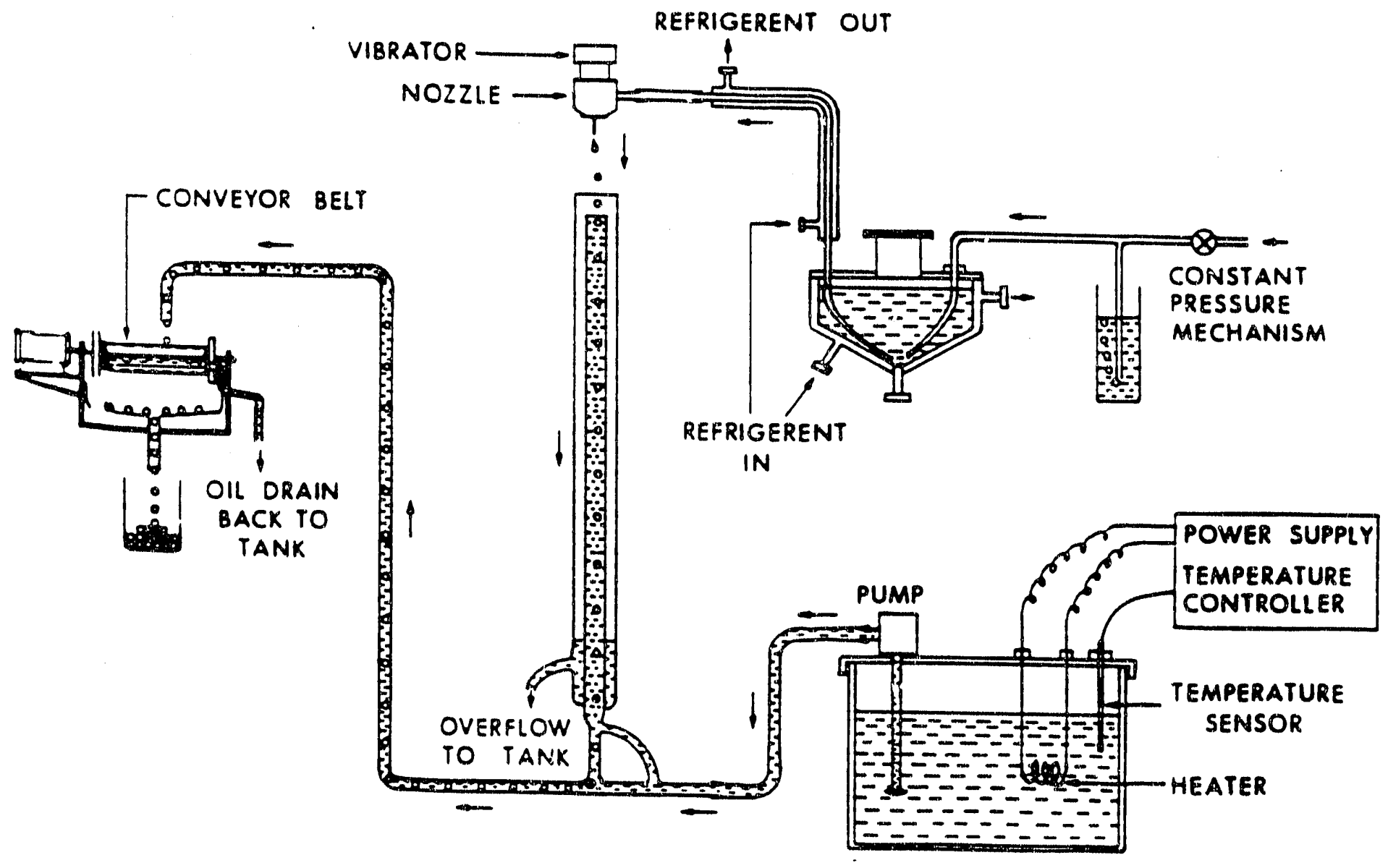

FIGURE 2. CONCEPTUAL APPARATUS NOR PRODUCTION OF MICROSPHERES VIA THE SOL-GEL PROCESS. 

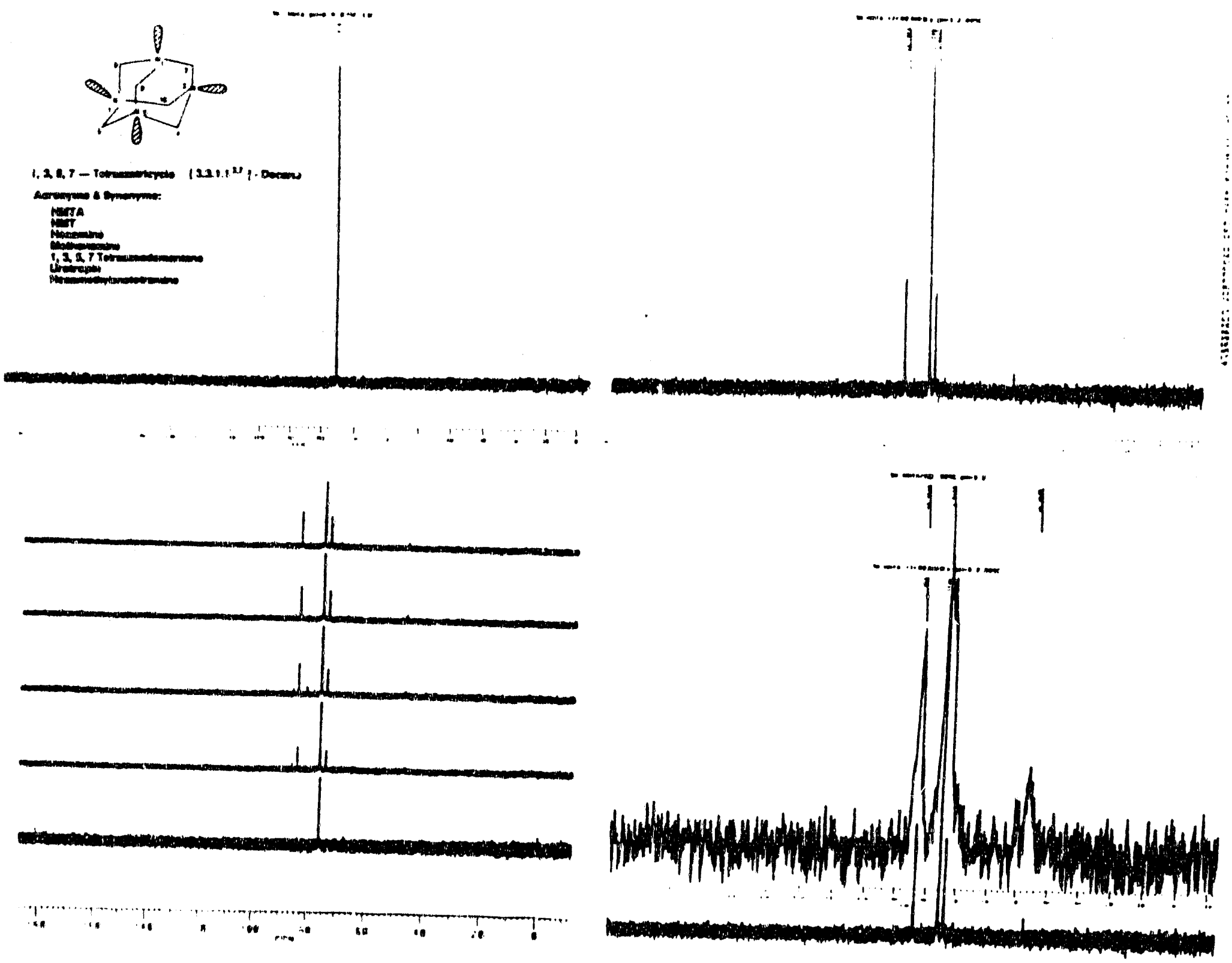

FIGURE 3. ${ }^{13} \mathrm{C}$ NMR OF 3M HMTA SOLUTIONS AND GELS.
a) $3 \mathrm{M} \mathrm{HMTA} / \mathrm{pH} 8.9 / 75^{\circ} \mathrm{C}$
b) $3 \mathrm{M} \mathrm{HMTA} / \mathrm{pH} 3.2 / 85^{\circ} \mathrm{C}$
c) $3 \mathrm{M} \mathrm{HMTA} / \mathrm{pH} 3.2 / 85^{\circ} \mathrm{C}$ as a $\mathrm{f}$ (Time)
d) Uranyl Gel/3MHMTA/3MUrea/pH $3.2 / 85^{\circ} \mathrm{C}$ 


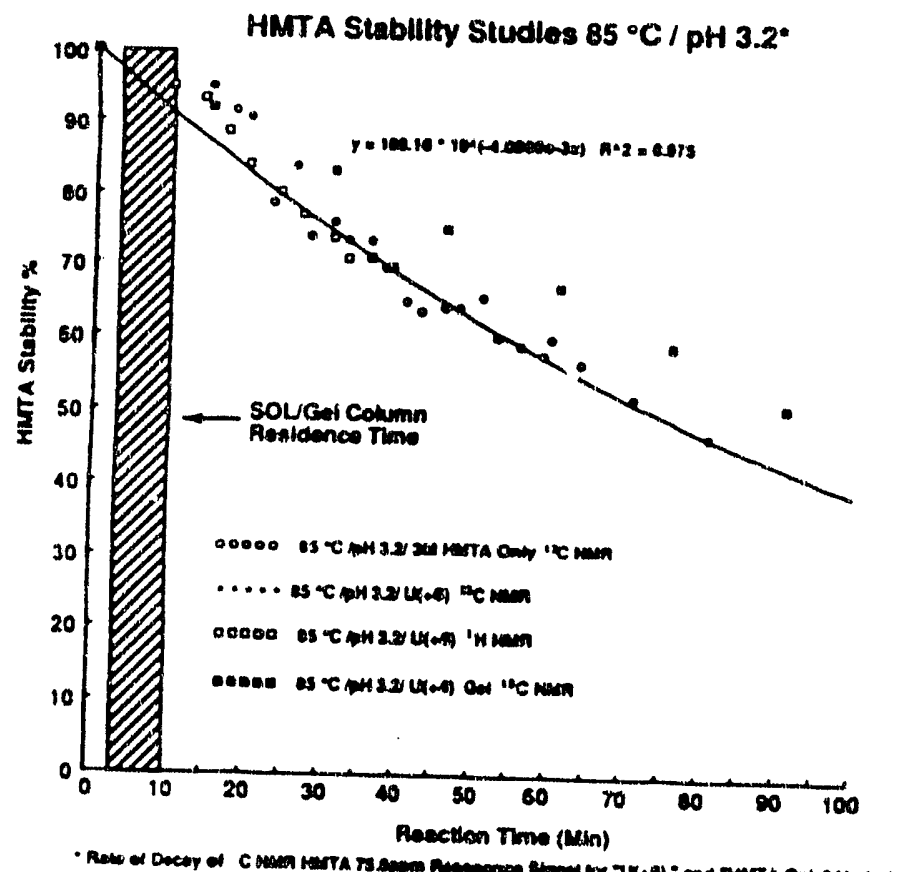

HMTA HYDROLYSIS

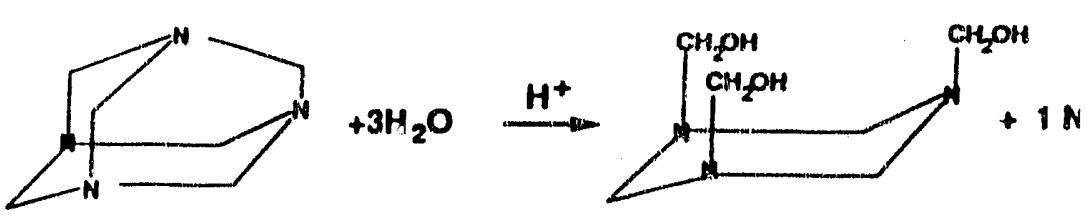

A $\left(\mathrm{C}_{6} \mathrm{H}_{12} \mathrm{~N}_{4}\right)$

B

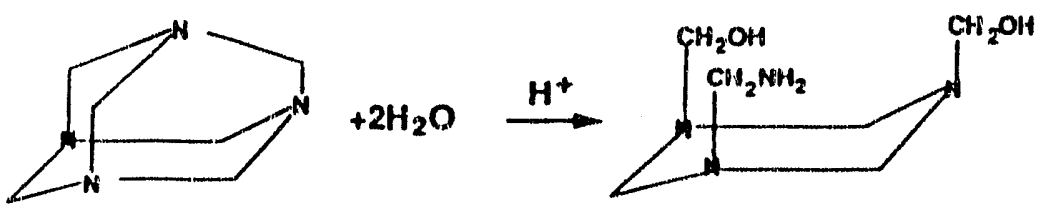

A $\left(\mathrm{C}_{6} \mathrm{H}_{12} \mathrm{~N}_{4}\right)$

- $\mathbf{B}^{\prime}$ Is Amino Byproduct formed to sllght extent consistent with HMTA Hydrolysis Mechanlem.

FIGURE 4. HMTA HYDROLYSIS.

a) Hydrolysis Rate Based on ${ }^{13} \mathrm{C}$ NMR Signal Integration

b) HMTA Structural Modifications During Hydrolysis Based on ${ }^{1} \mathrm{H} \&{ }^{13} \mathrm{C}$ NMR Assignments 


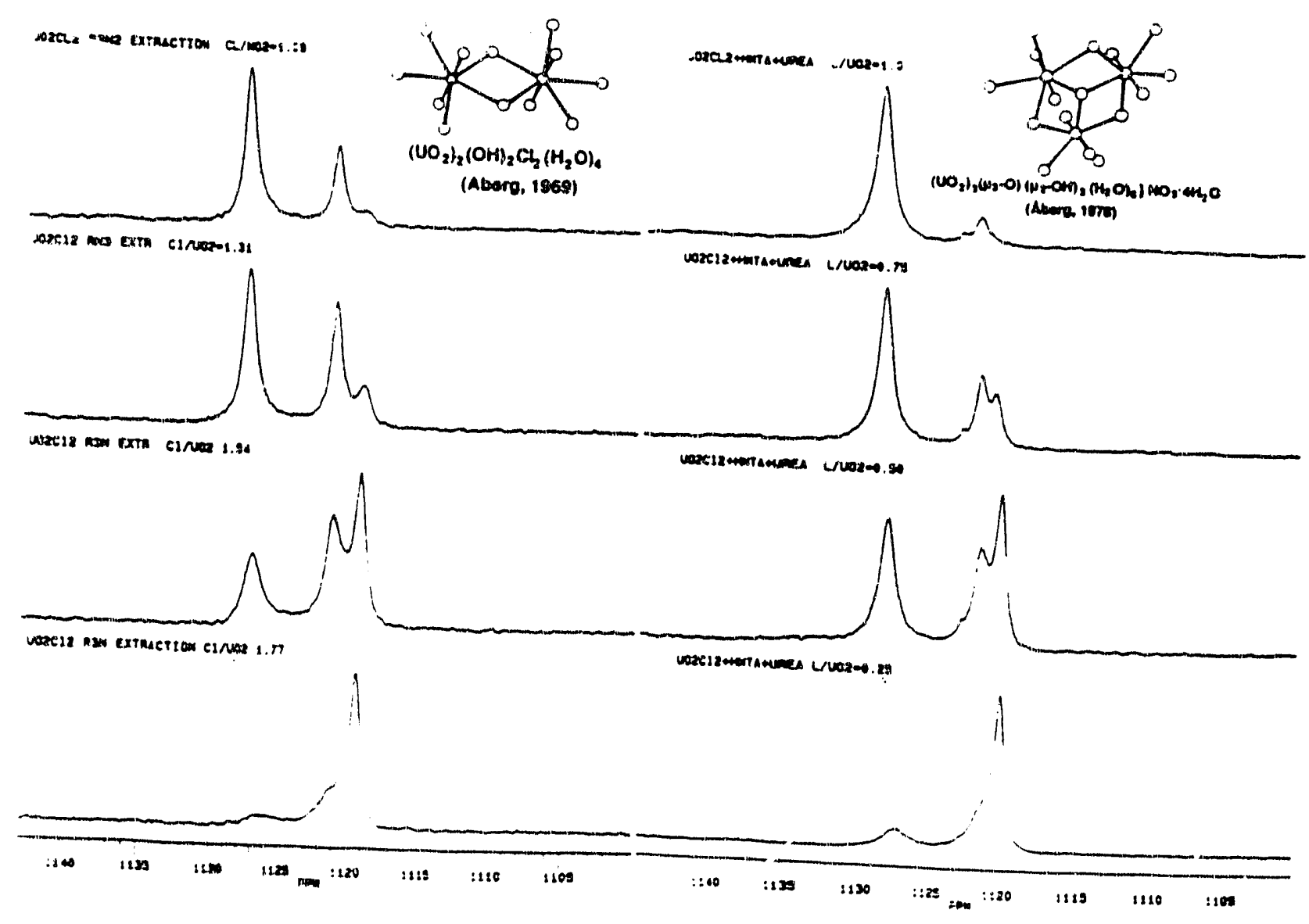

FIGURE 5. ${ }^{17} \mathrm{O}_{\mathrm{NMR}}$ OF $\mathrm{UO}_{2}{ }^{++}$HYDROLYSIS FRAGMENTS IN THE AXIAL OXYGEN REGION.

a) Synthetic "SOL" via Tri-n-Decyl Amine Extraction

b) Uranyl Gel Induced by HMTA Addition 


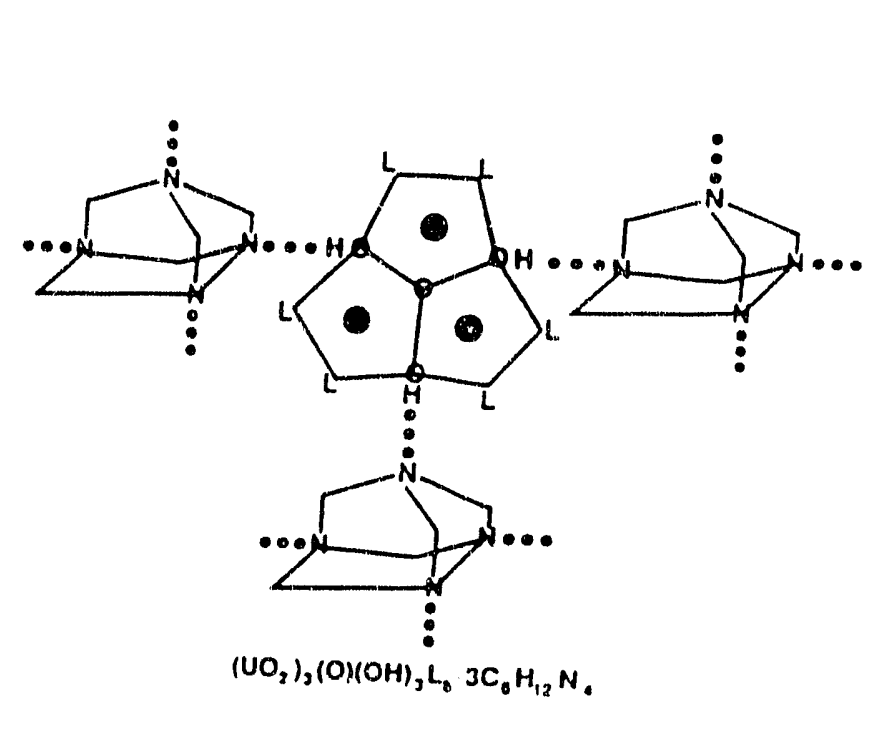

FIGURE 6.

URANYL TRIMER COMPLEX WITH UREA AS EQUTTORIAL LIGAND AND HMTA IN

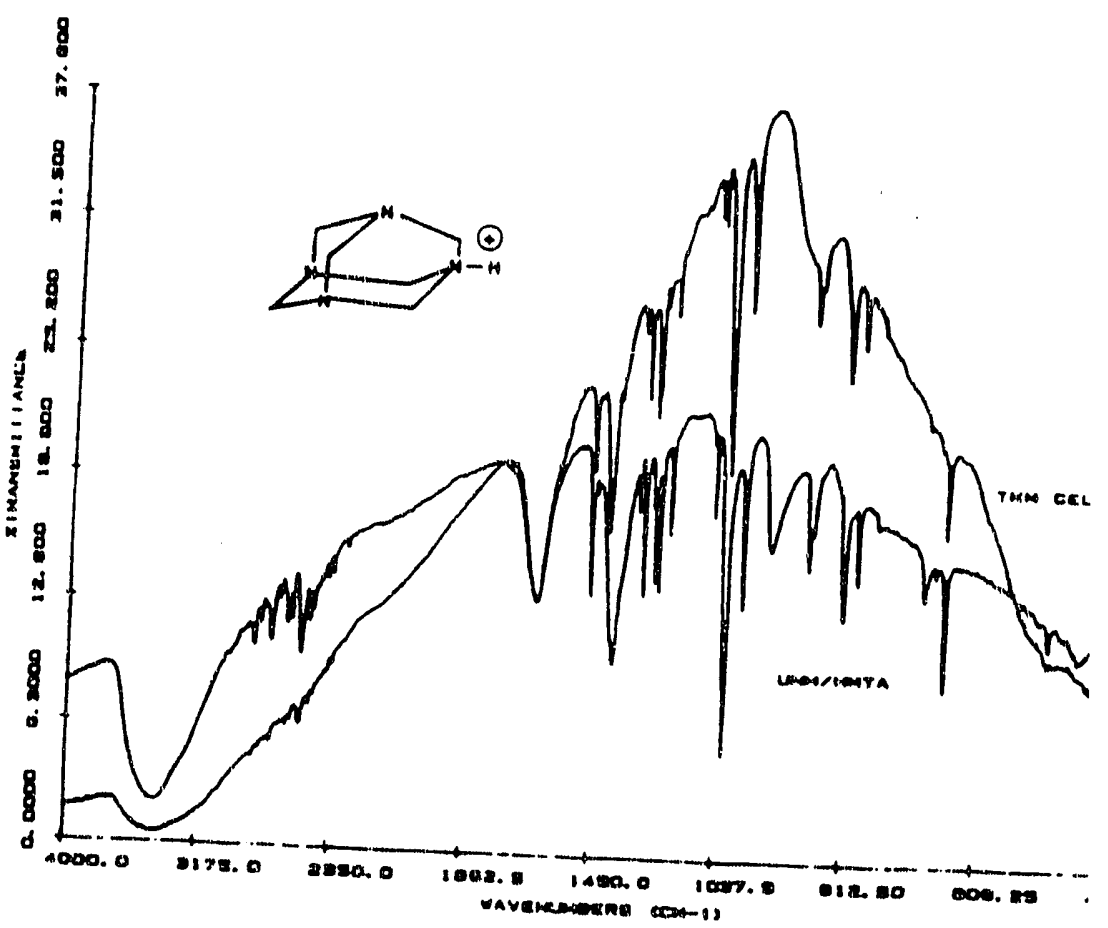
HYDROGEN BONDING.

FIGURE 7.

FOURIER TRANSFORM INFRARED SPECTRUM (FTIR) OF HMTAH+ IN A URANYL GEL. 

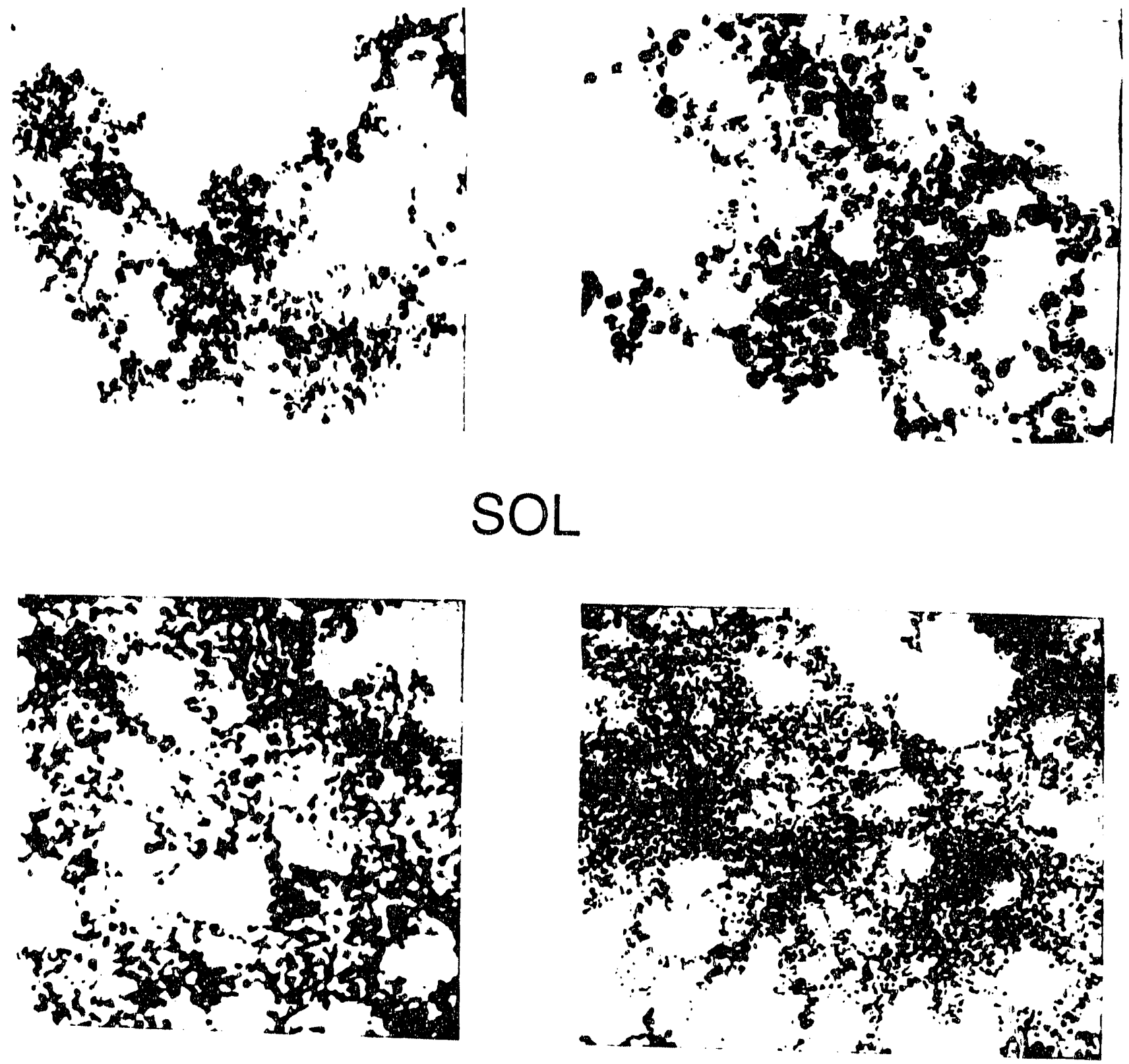

GEL

FIGLRE 8. TRANSMISSION ELECTRON MICROGRAPHS (TEM) OF THE SOL TO GEL TRANSITION INDUCED BY HMTA. 

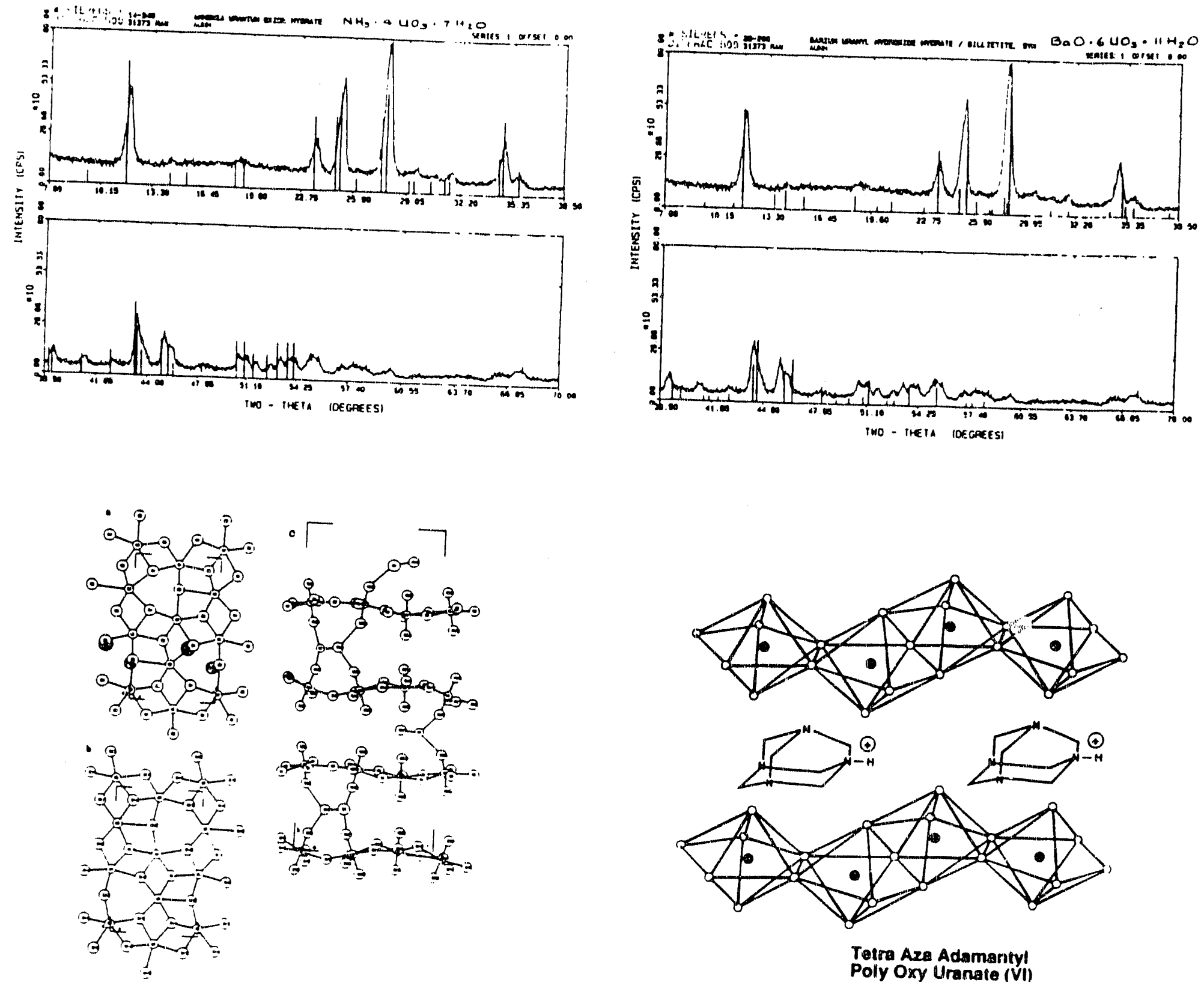

Totra Aze Adamanty! Poly Oxy Uranate (VI) FIGURE 9. X-RAY POWDER DIFFRACTION PATTERNS (XRPD) OF
HYDROUS URANIUM OXIDE POLYMERS.
a) Gel-Like Synthetic Ammonium Derivative Versus $4 \mathrm{UO}_{3} \cdot \mathrm{NH}_{3} \cdot 7 \mathrm{H}_{2} \mathrm{O}$
b) Billietite $\left(\mathrm{BaO}_{6} 6 \mathrm{UO}_{3} \cdot 11 \mathrm{H}_{2} \mathrm{O}\right)$ Versus Synthetic $4 \mathrm{UO3} \cdot \mathrm{NH} \cdot 7 \mathrm{H} 2 \mathrm{O}$ c) The Structure of Billietite Showing Layer Pattern and
Barium Intercalation

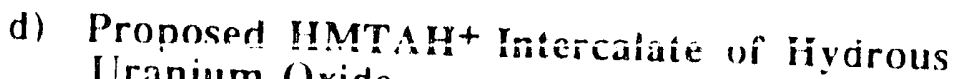 Uranium Oxide. 


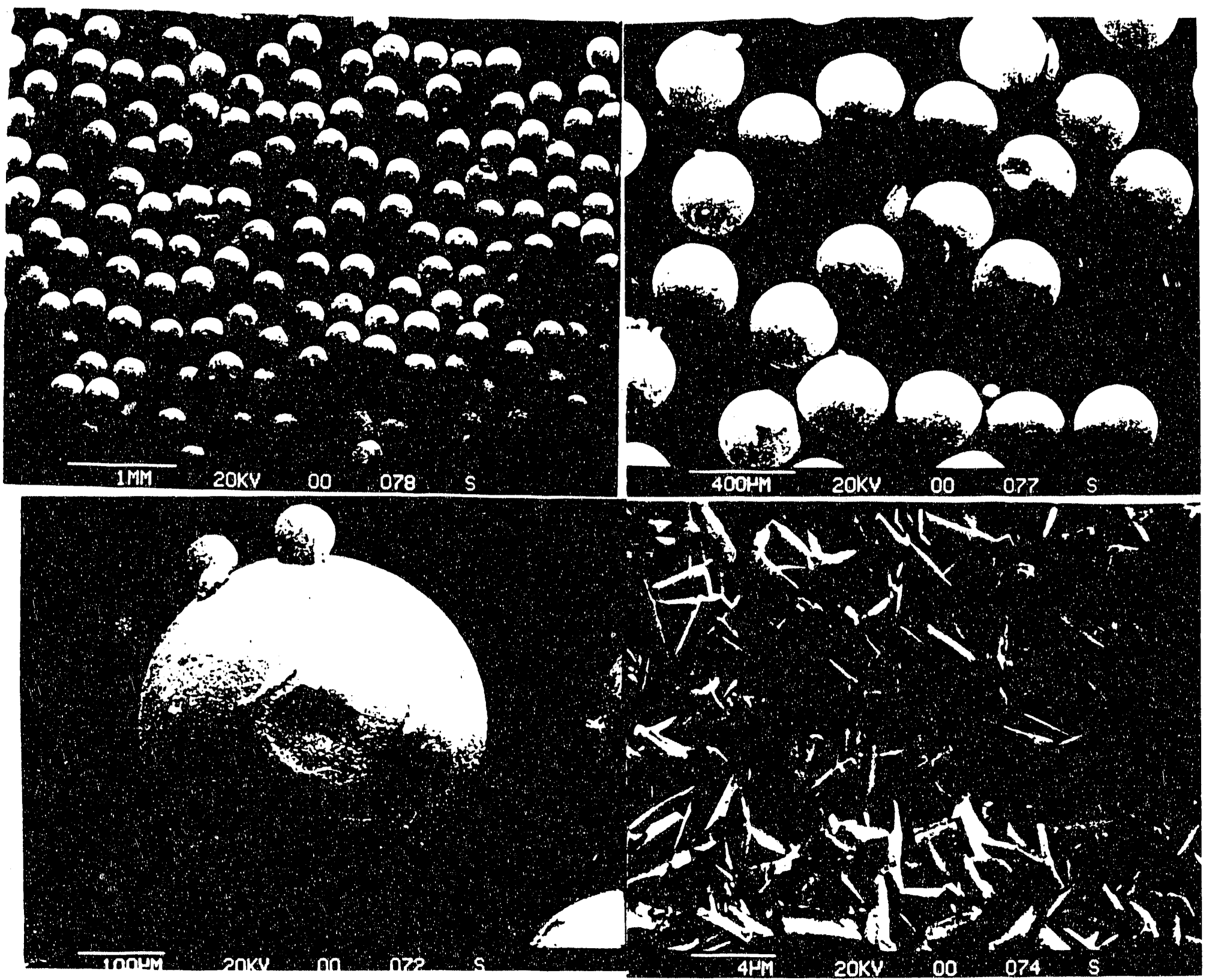

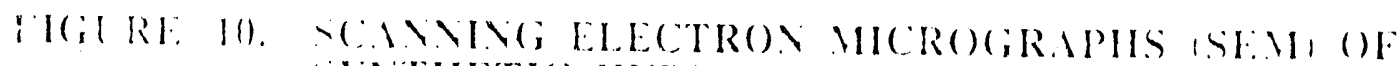
SYNTHETIC HYDROLS LRAVILU (OXIDE

IICROSPHERES.

(a) Is $\mathrm{x}$ Magnification

1. $=11$

$(1) 150$ I

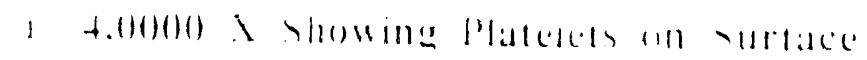



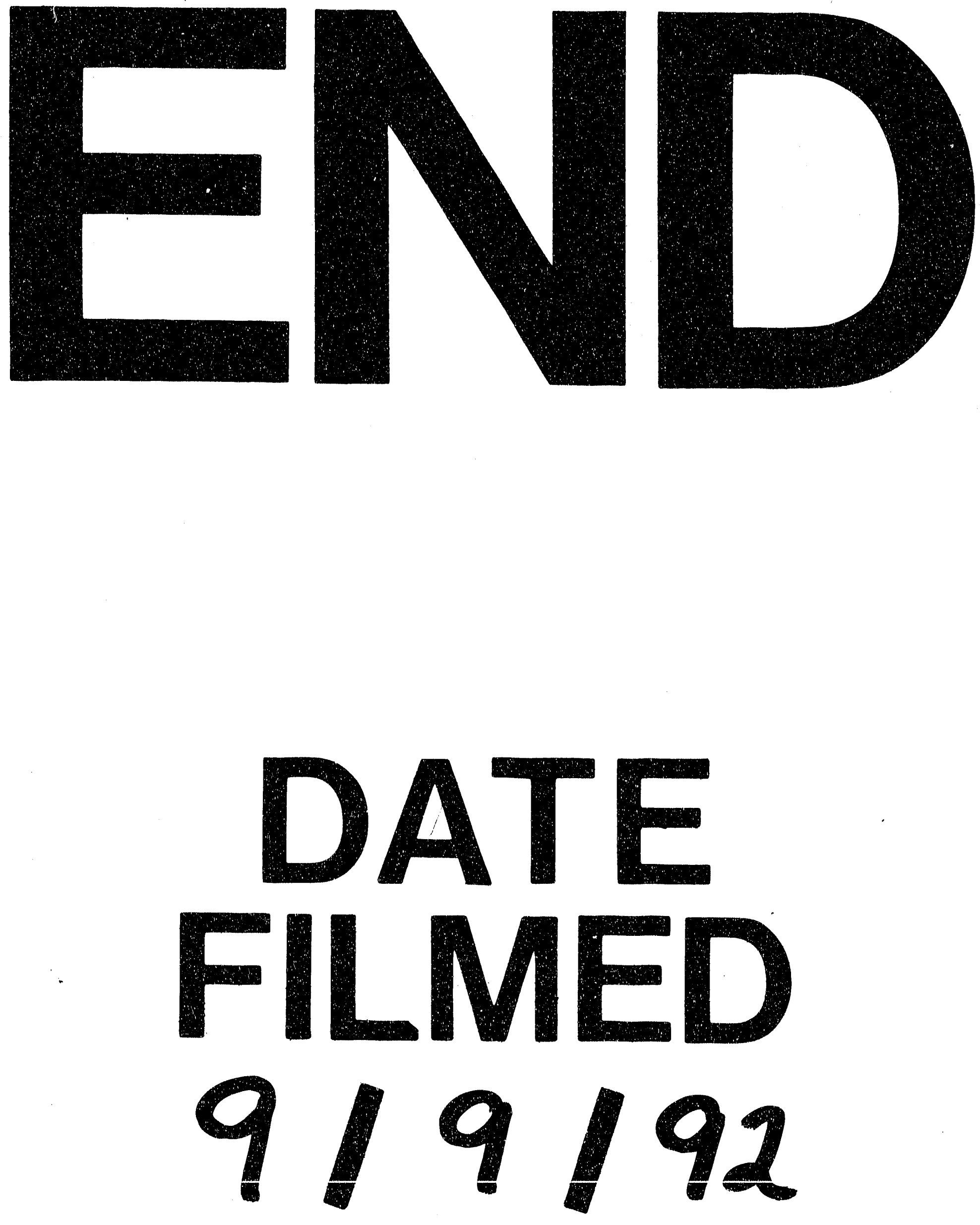

事 
